\title{
The Appropriation of Product Design as Solution to Minimise Risk of Exertional Heat Illness among Marathon Runners
}

\author{
Mohd Najib Abdullah Sani ${ }^{1, *}$, Azrul Amri Amran ${ }^{1}$, Muhammad Jameel Mohamed Kamil ${ }^{1}$, \\ Hanim Romainoor ${ }^{2}$, Louis Ringah Kanyan ${ }^{3}$ \\ ${ }^{1}$ Department of Product Design, Universiti Sains Malaysia, USM, 11800, Penang, Malaysia \\ ${ }^{2}$ Department of Graphic Communication Design, Universiti Sains Malaysia, USM, 11800, Penang, Malaysia \\ ${ }^{3}$ Design Technology Programme, Universiti Malaysia Sarawak, Kota Samarahan, 94300, Sarawak, Malaysia
}

Received September 22, 2020; Revised November 26, 2020; Accepted December 22, 2020

\begin{abstract}
Cite This Paper in the following Citation Styles
(a): [1] Mohd Najib Abdullah Sani, Azrul Amri Amran, Muhammad Jameel Mohamed Kamil, Hanim Romainoor, Louis Ringah Kanyan, "The Appropriation of Product Design as Solution to Minimise Risk of Exertional Heat Illness among Marathon Runners," International Journal of Human Movement and Sports Sciences, Vol. 8, No. 6A, pp. 63-67, 2020. DOI: $10.13189 /$ saj.2020.080711.
\end{abstract}

(b): Mohd Najib Abdullah Sani, Azrul Amri Amran, Muhammad Jameel Mohamed Kamil, Hanim Romainoor, Louis Ringah Kanyan (2020). The Appropriation of Product Design as Solution to Minimise Risk of Exertional Heat Illness among Marathon Runners. International Journal of Human Movement and Sports Sciences, 8(6A), 63-67. DOI: 10.13189/saj.2020.080711.

Copyright $\mathrm{C} 2020$ by authors, all rights reserved. Authors agree that this article remains permanently open access under the terms of the Creative Commons Attribution License 4.0 International License

\begin{abstract}
The intensity of environmental heat stress during a marathon race increases the runner's metabolic heat production. Based on series of participatory studies and interview sessions with 100 respondents among runners, the contributing factors to this homeostatic imbalance risk are the excessive amount of body-water deficit from extensive sweating, and the rapid increase of cardiovascular and thermal strain while running. In addition, environmental factors such as humidity, the increase of air temperature, wind speed and solar radiation contribute to the marathon runner's low performance during running with the paucity of cooling strategy that results in the increase of core body temperature with symptoms of exertional heat illness. This paper elucidates the integration of the statistical and theoretical studies of exertional heat illness and the human physiological responses complementing with the product design context. The integration demonstrates the synchronisation of design thinking process within the ergonomics ergosystem framework to develop the appropriate prototype design for marathon runners. As outcome, this research has successfully developed a running suit as its design proposal to minimise exertional heat illness risk and promote the runner's safety, wellbeing and performance in the heat.
\end{abstract}

Keywords Environmental Heat Stress, Exertional Heat Illness, Design Thinking, Prototype Design

\section{Introduction}

This paper is a study about the risk of exertional heat illness among marathon runners within the context of product design research. The main objective of this paper is to demonstrate the possible extension of the statistical and theoretical studies complementary with the design practice that aims to generate further product design innovation coherency to the user need through the development of Vapor $\mathrm{X}$ suit prototype design. Furthermore, this study demonstrated de Looze [1] propagation on (1) comfort is affected by factors of a various nature (physical, physiological, psychological) and (2) comfort is a reaction to the environment. The development of this Vapor X suit was based on the ergonomics ergosystem framework. This framework was adopted from the structural ergonomics view of work system by Bridger [2] (Figure 1) and adapted by Mohd Najib [3] (Figure 2). The framework consists of sets of 
elements that relate between one another to the surrounding parameters. The foundation of the framework consists of the synchronisation of 'people' and 'machine' interactions to form a function towards designing and producing some form of output. The auxiliary elements in the form of matter, design criteria and information, supply input that varies between the levels of human performance research as propagated by Bridger [2]. This research adapted the framework as a template for the optimisation of the system's operations to develop the Vapor X suit. This template can also be applied to other design disciplinary fields such as industrial design, engineering, environmental medicine and operations research. This study is considered as the first report to objectively understand the runner's endurance and physical condition during a marathon race. The study synchronises the application of ergonomics ergosystem framework with various factors that are taken into consideration such as human physics, psychology, anatomy, physiology and engineering, and utilises the Design Thinking process to illuminate the improved thermal sensation and thermal comfort of the Vapor X marathon running suit design. The explanation provided in relation to the Ergonomics and Design Thinking relevancies, the demonstration of the prototype design process aspires to give a larger spectrum to the body of knowledge that would in turn lead to further design research exploration based on the integration of cross-disciplinary studies with Sports Science relevancy.
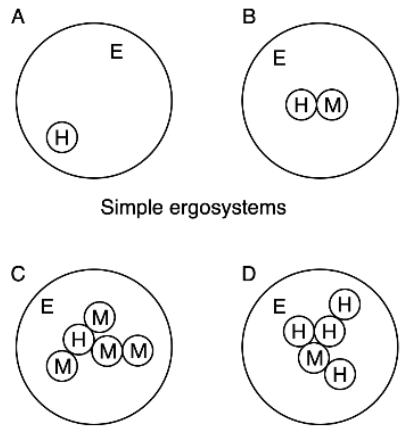

Complex ergosystems

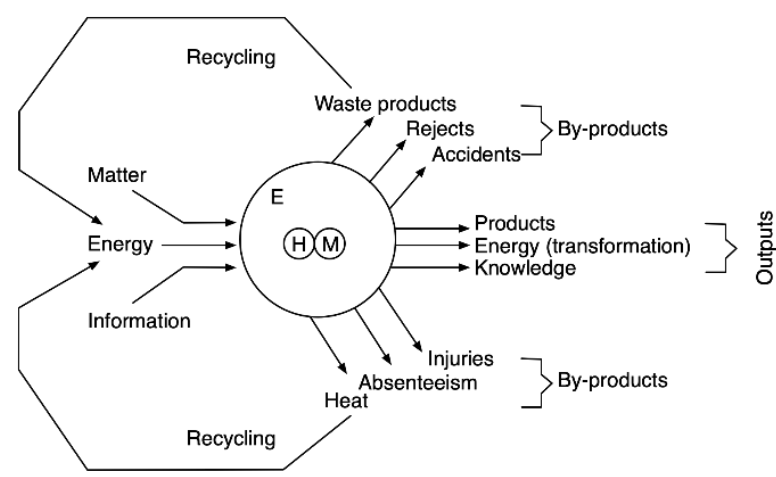

Figure 1. The structural ergonomics view of the work systems (Ergosystem) as propagated by Bridger [2].

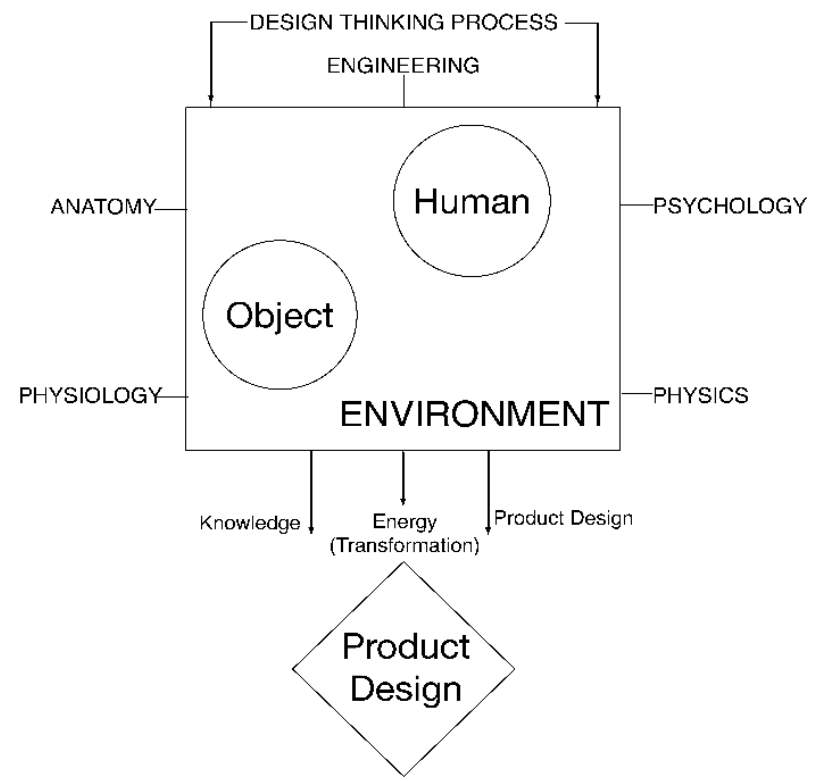

Figure 2. The Mohd Najib [3] ergosystem framework redesign based on Bridger [2] work system

\section{Materials and Methods}

The Vapor X suit was created to address the needs of the marathon runner to minimise the risk of exertional heat illness. A series of participatory studies were conducted to observe and experience the marathon race at 5 different series of local Malaysian marathon event, including interview sessions with 100 respondents among runners: 80 respondents during the day events and 20 at night event to understand further the runner's endurance and physical condition during the marathon race. The average temperature for the day events was $36^{\circ}$ to $37^{\circ}$ degree Celsius and $28^{\circ}$ degree Celsius at night.

\section{Symptoms of heat-related illness experienced by runners during a marathon race}

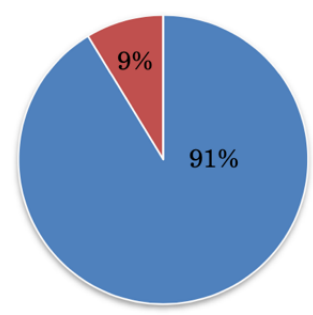

$$
\begin{aligned}
& \text { Dehydration, sweating } \\
& \text { muscle cramp, fatigue. } \\
& \text { Dehydration, dizziness, } \\
& \text { nausea, persistance muscle } \\
& \text { cramp, excessive sweating. } \\
& \text { Confusion, disorientation,loss } \\
& \text { of consciousness, vomiting, } \\
& \text { drowsiness, staggering. }
\end{aligned}
$$

Figure 3. The marathon runners' heat-related illness symptoms survey results based on the runners' responds at the 5 local marathon events.

\subsection{Design Development}

The design development process was steered by the foundation set by Lijuan Wang et. al [4], who investigated 
the effects of operative temperature and total heat losses, and the relationship between the heat loss and thermal sensation. Their research, that is also in accord with previous researchers such as Ouyang [5] on Clothes Hygiene, Hasebe et. al [6] Usefulness of ReR Interval and Its Variability in Evaluation of Thermal Comfort, Huizenga et. al [7] Skin and Core Temperature Response to Partial- and Whole-Body Heating and Cooling, Zhu [8] Building Environment, Shi [9] Numerical Simulation of the Influence of Clothing on Human Thermal Comfort and Wang and $\mathrm{Yu}[10]$ The Temperature-Regulating Function of Clothing, finds that the thigh, leg and chest experience much heat loss in low temperatures, while the chest, abdomen, thigh and head face great heat loss at higher temperatures. This data is significant for clothing design.
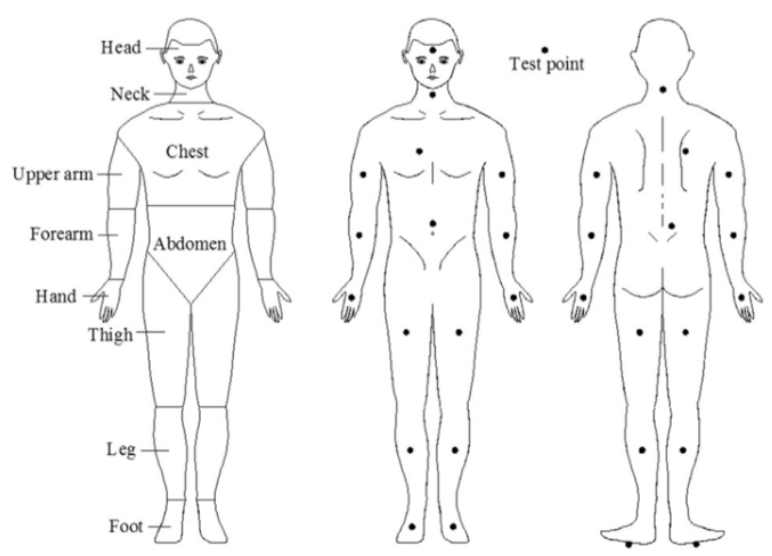

Figure 4. The divided parts of human body and the significant points of each part of the body tested by Lijuan Wang [4] for heat loss factors and effects

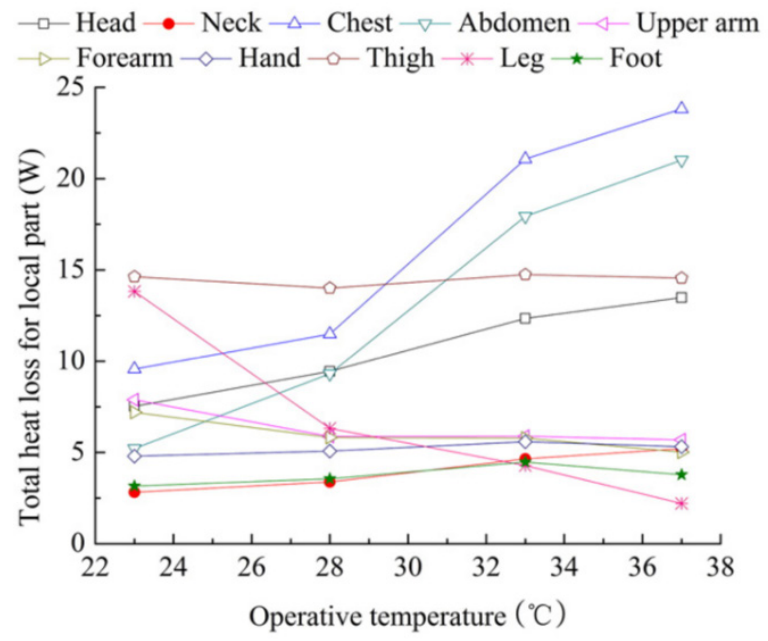

Figure 5. Lijuan Wang et. al [4] summary of total heat loss for the body, used as the foundation in prototyping the Vapor X suit.

Figure 5 establishes the significant guideline for clothing design. The design development involving the synchronisation of the ergonomics ergosystem framework and design thinking process that informs a comprehensible design direction is as follows:

\subsubsection{Phase 1}

Gaining an empathetic understanding of the problem.

\subsubsection{Phase 2}

Generating ideas and outlining the design criteria (Figure 6) based on understanding of the users and their needs and having analysed and synthesised the observations in Phase 1 to produce a human-centred problem statement. This involved brainstorming session, sketching, detail drawing on paper and technical 2D (Figure 7) and 3D CAD modelling.

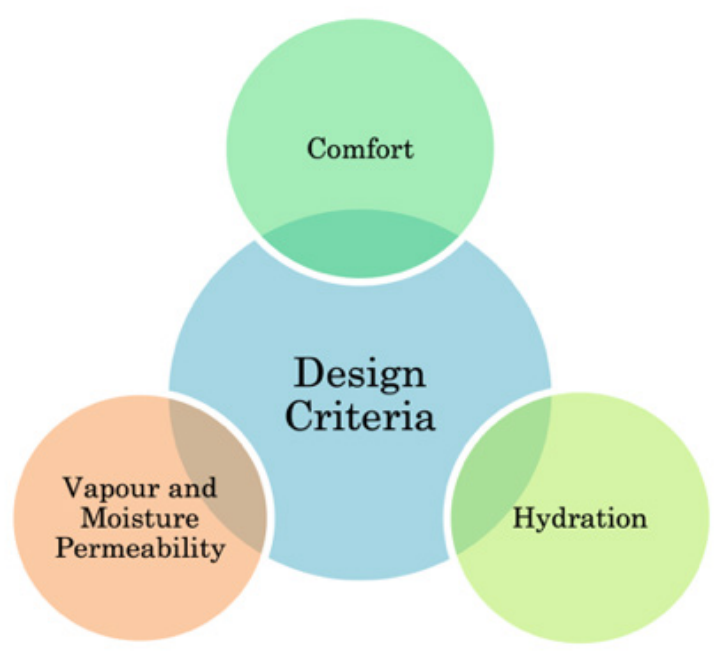

Figure 6. The Vapor $\mathrm{X}$ suit design criteria

\subsubsection{Phase 3}

The prototype technical aspects are investigated; flaws in the design were re-examined and rectified on the basis of the users' experiences. At the end of this stage, the researchers and designers obtain a better idea and clearer view of the constraints inherent to the running suit, understand how real users would behave, think and feel when using the end product (Figure 8).

\subsubsection{Phase 4}

Testing the completed Vapor $\mathrm{X}$ suit using the best solutions identified during the prototyping phase. Although this is the final stage of production, in an iterative process, alterations and refinements are made to rule out problem solutions and derive as deep an understanding of the running suit and its users as possible.

\subsubsection{Phase 5}

The final working prototype is established and confirmed following the serial iteration phases that involve garment alterations to fit the appropriate comfort of the user's psychological and physiological response. The aspects of aesthetic properties concerning the current sportswear style or fashion and the technical consideration emphasising on the garment ventilation system for the thermal and body movement comfort are the key properties confirming the finished end product. 

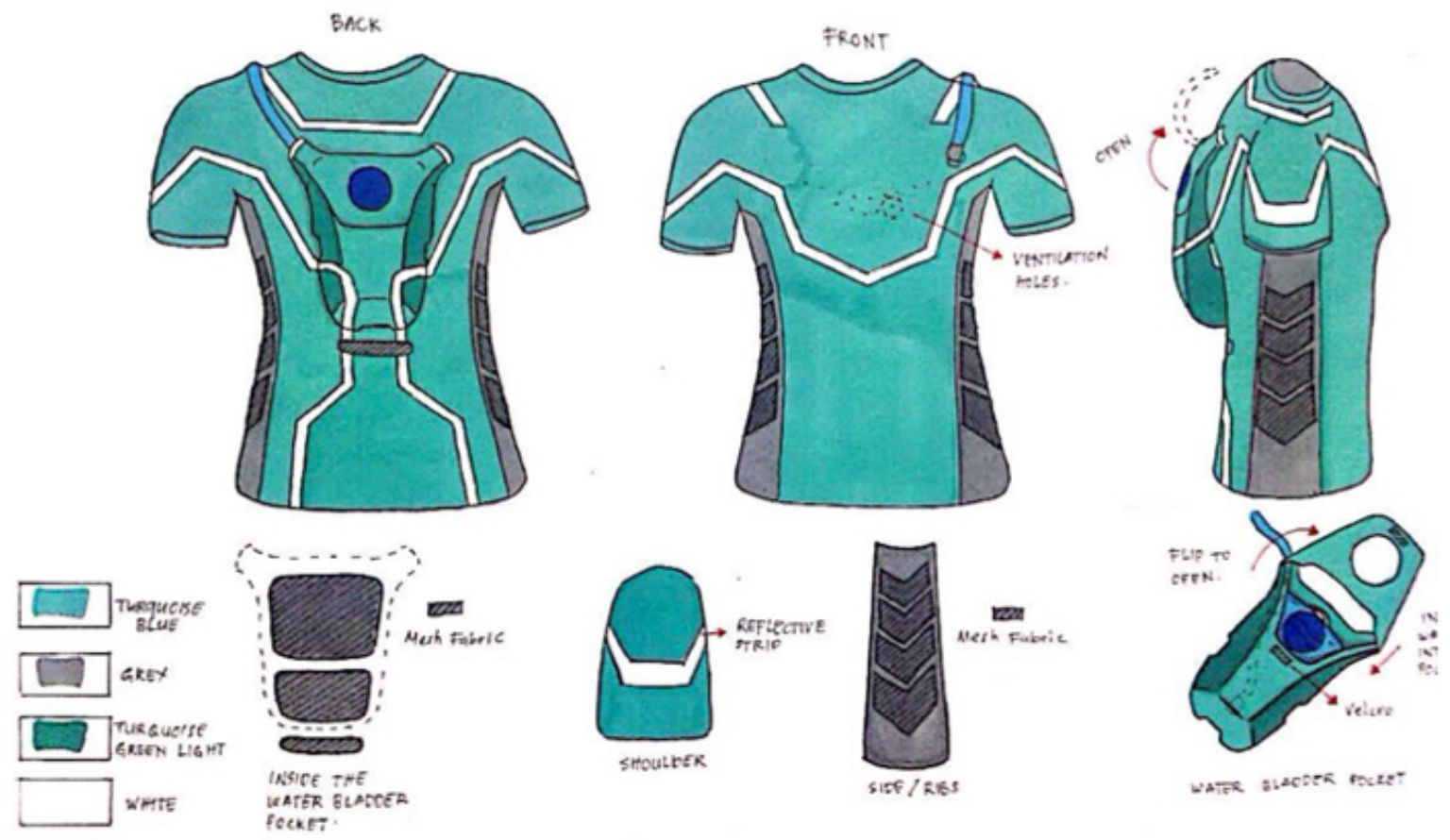

Figure 7. Detail drawing on paper and technical 2D.
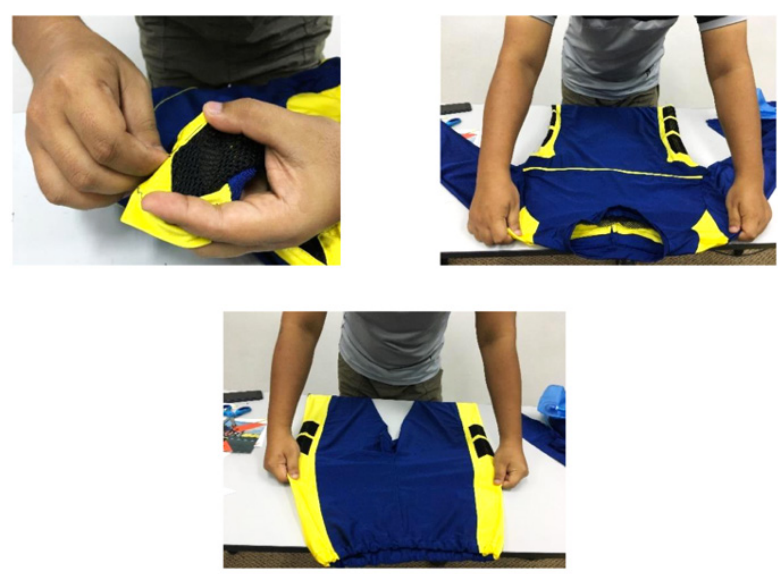

Figure 8. The prototyping processes

\subsection{Results and Discussion}

The design of the Vapor $\mathrm{X}$ suit has established the possible integration of the statistical and theoretical study complementing with the product design context. By implementing the design thinking process and aligned with the design criteria that comprises of (1) comfort, (2) vapour and moisture permeability and (3) hydration, Vapor X provides zonal cooling that incorporates ventilation system designed at the width of the chest and both sides of the suit high waist to dissipate heat and improve the runners' physiological response and cardio-respiratory fitness. The two-litre hydration bladder pocketed at the runner's dorsal, aggrandised the cooling and performance enhancement strategies featured in the

design of the running suit. The hydration bladder will be filled with water and cooled in the freezer prior to the running event. The bladder coldness will be sustained during the running and the runners warm body temperature will slowly melt the frozen water and making it convenient for the runner to drink from the hydration bladder tube that attached at the runner's shoulder. In terms of runners' safety on the road, this suit is also sewn with reflective fabric to ensure the runners' visibility during day and night running. The integration of Sports Science studies and the Product Design research context extend Vapor $\mathrm{X}$ sportswear definition to an unconventional perspective. The aesthetic design, the fusion of materials in the garment construction and prescribed with the ergonomics criterion have predominantly established this significance. In addition, the synchronization of the empathic protocol in the Design Thinking research process demonstrates the importance of user's input, given that the users are considered as significant stakeholder in design practice. In this regard, the functionality and the usefulness of designed product are determined by the issue addressed by the user. The Vapor X suit is a preventive countermeasure to enhance thermal comfort and a cooling strategy to minimise the risk of heat illness through the engagement of the product design research context. The design criteria have successfully outlined the user's need for thermal comfort in the running suit. However, user testing on the suit's performance is required to validate the appropriateness of the suit design to provide thermal comfort for the runner in a running event. 

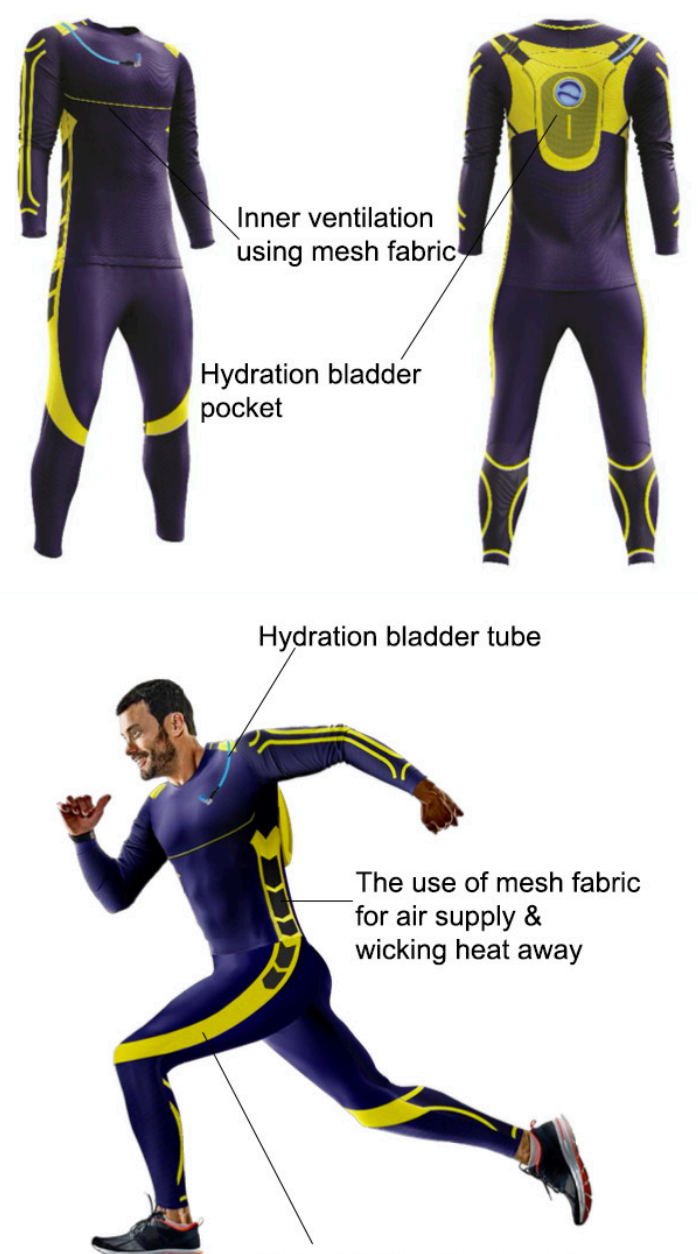

High visibility reflective fabric for runners safety

Figure 9. The Vapor $\mathrm{X}$ suit design tailored based on the total heat loss for local part and the cooling strategy outlined in the design criteria.

\section{Conclusions}

This research has successfully developed a running suit as its design proposal to minimise the risk of exertional heat illness, to promote runners' safety, their wellbeing and performance in the heat. Ergonomic comfort characteristics such as (1) thermo physiological comfort, (2) tactile comfort, (3) physical dexterity and (4) psychological comfort, are significant to the construction of active sports garments such as running, in parallel to what is proposed by Vishal and Rajesh [11]. What is associated with the construction of comfort running suit is the use of knitted microfiber polyester fabric that promotes greater body dynamic movements and the transmission of body vapour.

\section{Acknowledgements}

Vapor X copyright number: AR2018005138 is patented under the ownership of Universiti Sains Malaysia.

\section{REFERENCES}

[1] de Looze,M.P., Kuijt-Evers,L.F.M., Dieën,J.V. . Sitting Comfort and Discomfort and The Relationship With Objective Measures, Ergonomics, Vol.46, No.10, 985-997, 2003.

[2] Bridger, R.S. Introduction to Ergonomics, CRC Press, Boca Raton FL, 2009.

[3] Mohd Najib, Abdullah Sani. The Sitting Posture and Behaviour for Floor-Sitting Furniture Design In Malaysia, FACA UNIMAS, Kota Samarahan, Sarawak, 2015.

[4] Lijuan, Wang Hui, Yin Yuhui, Di Yanfeng, Liu Jiaping, Liu. Human local and total heat losses in different temperature, Journal of Physiology and Behavior, No.157, 270-276, 2016.

[5] Ouyang, H. Clothes Hygiene, People's Military Medicine Press, Beijing, 1985 (in Chinese).

[6] Hasebe, H., Iriki, M., Takahasi, K. Usefulness of ReR interval and its variability in evaluation of thermal comfort, Int.J.Biometeorol, Vol.38, 116-121, 1995.

[7] Huizenga, C. Zhang, H. Arens, E. Wang, D. Skin and core temperature response to partial- and whole-body heating and cooling, J. Therm. Biol., Vol29, 549-558, 2004.

[8] Zhu, Y.X. Building Environment, China Building Industry Press, Beijing, 2005 (in Chinese).

[9] Shi, X.K. Numerical Simulation of the Influence of Clothing on Human Thermal Comfort, Master Thesis, Dong Hua University, 2003 (in Chinese).

[10] Wang, L.B., Yu, Y.Q. The temperature-regulating function of clothing, J. Shand. Coll Text Technol., Vol.10, 16-21, 1995.

[11] Vishal Kejkar, Rajesh, Dhore. Active Sportswear Fabrics, Journal of Trends in Textile Engineering \& Fashion Technology, Vol.5, No.2, 603-608, 2019. 